\title{
Rotating Arrays of Orchid Flowers: A Simple and Effective Method for Studying Pollination in Food Deceptive Plants
}

\author{
Daniela Scaccabarozzi ${ }^{1,2,3, * \mathbb{C}}$, Andrea Galimberti ${ }^{4}\left(\mathbb{D}\right.$, Kingsley W. Dixon $^{1}$ \\ and Salvatore Cozzolino ${ }^{2}$ \\ 1 School of Molecular and Life Sciences, Curtin University, Bentley, WA 6102, Australia; \\ kingsley.dixon@curtin.edu.au \\ 2 Department of Biology, University of Naples Federico II, 80126 Naples, Italy; cozzolin@unina.it \\ 3 Department of Biodiversity and Attractions, Conservation Kings Park Science, Perth, WA 6005, Australia \\ 4 Dipartimento di Biotecnologie e Bioscienze, Università degli Studi di Milano-Bicocca, 20126 Milano, Italy; \\ andrea.galimberti@unimib.it \\ * Correspondence: daniela.scaccabarozzi@postgrad.curtin.edu.au
}

Received: 27 May 2020; Accepted: 19 July 2020; Published: 22 July 2020

\begin{abstract}
Floral deception has been observed in several genera in angiosperms, but is most common in the Orchidaceae. Pollination mechanisms in food deceptive plants are often difficult to assess, as visitation frequency by insects requires numerous hours of field observations to ascertain. Here, for the first time, we describe in detail and validate a simple and effective method that extends previous approaches to increase the effectiveness of pollination studies of food deceptive orchids. We used an orchid of southwest Australia, Diuris brumalis (Orchidaceae), that visually mimics model plants belonging to the genus Daviesia (Faboideae). Arrays of orchid flowers were placed and moved systematically in proximity to model plants, resulting in rapid attraction of the pollinators of $D$. brumalis. We compared pollinaria removal (as an indicator of pollination success) in naturally growing orchids with pollinaria removal in arrays of orchid flowers in the same sites. We showed that the proposed method greatly enhances pollinator attractiveness in food deceptive systems with very low pollination rates, and we compared its efficiency with other similar methods. The approach can be used for observing pollinator behavioural patterns and confirming effective pollinators for food deceptive species with low insect visitation rates.
\end{abstract}

Keywords: bait orchids; food deception; pollinator attraction; pollinator observation

\section{Introduction}

Floral deception has been observed in several hundred genera of angiosperms [1], but is most common in the Orchidaceae where approximately 8000 species are believed to not have floral rewards for pollinators [2,3]. Deceitful orchids lure their pollinators by many mechanisms that include generalised food deception, through target mimicry of other flowers that do produce food such as nectar or pollen, mimicking carrion odour and providing insect brood-sites or shelters, as well as by sexual deceit, utilising pheromone attraction of insects [4]. Food deceptive orchids typically attract pollinators by mimicking some of the floral traits of neighbouring rewarding species, such as inflorescence shape and architecture, flower colour and brightness, scent, nectar guides and pollen marks [5-7]. Despite food deception being a predominant strategy among deceptive orchids [8], especially in Australia, it has been less studied relative to sexual deceit of specialised male pollinators.

The lack of nectar in deceptive orchids can lead to low visitation rates of pollinators and pollination success [9-11], up to $30 \%$ lower relative to rewarding orchids [12]. Visually deceptive 
orchids in Western Australia show a variable range of reproductive success (0-48\% fruit set) with several species experiencing a fruit set close to zero in some flowering seasons [13]. This can be due primarily to pollinators that quickly learn to avoid fraudulent orchids [14,15]. Infrequent visits by pollinators extend the time necessary to carry out the observations, making the identification of effective pollinators tedious. For sexually deceptive orchids, Stoutamire [16] and Peakall [17] developed a method of floral presentation via baiting stations that has been deployed widely, and revisited in other orchids showing sexual mimicry strategies, for almost 50 years (Table 1, i.e., Drakaea glyptodon Fitzg.; e.g., [18-23]). In food deceptive orchids, a different "baiting station" approach, based on a bifurcated stick presenting two inflorescences (one of the mimic species and another one of the model species) has been developed with the precise aim to compare pollinator preference between the mimic orchid and its rewarding model plants (i.e., pollinator choice or bee interview technique (Table 1) [24-27]). In greater detail, the latter approach was used in Disa pulchra Sond. to test whether pollinators discriminated between mimic and model plants, while in Orchis morio (Anacamptis morio (L.) R.M.Bateman, Pridgeon \& M.W.Chase) and Platanthera chlorantha (Custer) Rchb. it was used to measure the effect of different nectar amounts on insect visitation rates.

During a study of the food deceptive orchid Diuris brumalis D.L.Jones in southwest Australia, we developed an alternative strategy to consistently attract pollinators which were difficult to observe due to their low visitation rates and fleeting floral visitation times (often $\leq 1 \mathrm{~s}$ ) [28]. In D. brumalis there was evidence of visitation by a potential panel of pollinator species (i.e., Trichocolletes spp., Hymenoptera, Colletidae), but, despite several hours of observation, the removal of pollen by this pollinator species was never observed, resulting in the absence of pollinator confirmation. Thus, Scaccabarozzi et al. [28] used arrays of orchid flowers in proximity to model plants to attract more pollinators than would typically be gained by observing stationary plants in their natural fashion.

Diuris brumalis is a terrestrial winter flowering orchid, which is common in Darling Range near Perth, Western Australia [29]. Like congeneric species, it is capable of forming extensive clones by producing daughter tubers [30] (Figure 1). Diuris brumalis has been shown to mimic rewarding pea plants of the genus Daviesia Sm. (Faboideae), with which it shares pollinators (Trichocolletes spp.) [31] and floral visual cues such as shape and colour spectral reflectance [28] (Figure 1). Based on the mimicry pollination syndrome of multiple pea species in the genus Daviesia (Figure 1) [28], we developed and validated a method that involves systematically moving artificial arrays of the orchid D. brumalis to enhance attractiveness for insects, and therefore increase the number of pollinator observations required to determine insect behavioural patterns. As D. brumalis grows in clonal groups [30], Scaccabarozzi et al. [28] adapted the sexual deceptive baiting method and revisited the original approach [17] to create artificial arrays or clumps of flowers [28]. In fact, several attempts applying random baiting or choice experiments (Table 1) in D. brumalis did not lead to any improvement in pollinator visitation. The originality of the method consists of systematically rotating these arrays relative to the position of model plants. By doing so, Scaccabarozzi et al. [28] were able to attract a larger number of effective pollinators for D. brumalis. Our study aims to (i) describe in detail how to use this method, (ii) validate its effectiveness for increasing pollinator attraction in a food deceptive orchid system, (iii) provide recommendations for its application in other food deceptive orchids and (iv) provide a detailed comparison of its efficiency with other similar methods. Specific objectives based on the $D$. brumalis study system were to compare the pollination success of naturally growing orchids and arrays of orchid flowers, and to assess the limitations of the current method for wider application, and its efficiency relative to other similar methods. 
Table 1. Methods for conducting orchid pollination studies on insect behavioural ecology; relative description; first application: reference to the author(s) that first applied the method; orchid study species; orchid fruit set (average); aim of application; on which pollination strategy the method was first applied (SD: sexual deception; GFD: generalised food deception; GFDF: generalised food deception with food foraging insects (minute amount of nectar produced by orchids); BFM: Batesian floral mimicry (food mimicry); NR: nectar reward); potential limitations of the methods.

\begin{tabular}{|c|c|c|c|c|c|c|c|}
\hline $\begin{array}{l}\text { Methods for Orchid } \\
\text { Pollination Studies }\end{array}$ & Description & First Application & $\begin{array}{c}\text { Study Orchid } \\
\text { Species }\end{array}$ & $\begin{array}{l}\begin{array}{l}\text { Orchid Fruit Set } \\
\text { (Average) }\end{array} \\
\end{array}$ & Aim & $\begin{array}{c}\text { Pollination } \\
\text { Strategy }\end{array}$ & Limitations \\
\hline \multirow{2}{*}{ Baiting Stations } & $\begin{array}{l}\text { picked inflorescences or } \\
\text { potted plants presented }\end{array}$ & $\begin{array}{c}\text { SD: Stoutamire, } \\
\text { 1974: Peakall, } 1990\end{array}$ & Drakaea glyptodon & $20 \%$ & \multirow{2}{*}{ attract pollinators } & $\mathrm{SD}$ & $\begin{array}{c}\text { SD: absence of males influences } \\
\text { the effectiveness }\end{array}$ \\
\hline & $\begin{array}{l}\text { randomly in the landscape; } \\
\text { from } 2 \text { to } 15 \text { min trials }\end{array}$ & $\begin{array}{l}\text { GFDF: Reiter et al., } \\
\text { 2018; } 2019\end{array}$ & $\begin{array}{l}\text { Caladenia versicolor } \\
\text { Caladenia concolor }\end{array}$ & $\begin{array}{c}50 \% \\
30.5 \%\end{array}$ & & GFDF & $\begin{array}{l}\text { GFD: proximity to nest sites } \\
\text { influences the effectiveness }\end{array}$ \\
\hline $\begin{array}{l}\text { Choice Experiment or } \\
\text { Bee Interview } \\
\text { Technique }\end{array}$ & $\begin{array}{l}\text { a bifurcated stick presenting } \\
\text { two inflorescences (one of the } \\
\text { mimic species and another } \\
\text { one of the model species, or } \\
\text { two orchid inflorescences } \\
\text { depending on the strategy) }\end{array}$ & $\begin{array}{l}\text { Thomson, 1988; } \\
\text { Johnson \& Nilsson, } \\
\text { 1999; Johnson, } \\
2000\end{array}$ & $\begin{array}{l}\text { Disa pulchra } \\
\text { Orchis morio } \\
\text { Platanthera } \\
\text { chlorantha }\end{array}$ & $\begin{array}{l}15 \% \\
51 \% \\
29 \%\end{array}$ & $\begin{array}{l}\text { test for food mimicry } \\
\text { or test for nectar effect } \\
\text { on visitation rate }\end{array}$ & $\begin{array}{l}\text { BFM } \\
\text { GFD } \\
\text { NR }\end{array}$ & $\begin{array}{l}\text { when the pollination success is } \\
\text { low, sufficient replicas are not } \\
\text { warranted; presence of nest } \\
\text { sites influences the effectiveness }\end{array}$ \\
\hline Rotating Arrays & $\begin{array}{l}\text { systematic rotation of arrays } \\
\text { of orchid flowers (picked } \\
\text { inflorescences) relative to the } \\
\text { position of various model } \\
\text { plants; } 15 \text { min trials }\end{array}$ & $\begin{array}{l}\text { Scaccabarozzi } \\
\text { et al., 2018; } 2020\end{array}$ & $\begin{array}{l}\text { Diuris brumalis, } \\
\text { Diuris magnifica }\end{array}$ & $3 \%$ & $\begin{array}{l}\text { increase the visitation } \\
\text { rate by insects }\end{array}$ & BFM & $\begin{array}{l}\text { presence and abundance of } \\
\text { rewarding model plants } \\
\text { determines the effectiveness }\end{array}$ \\
\hline
\end{tabular}




\section{A}

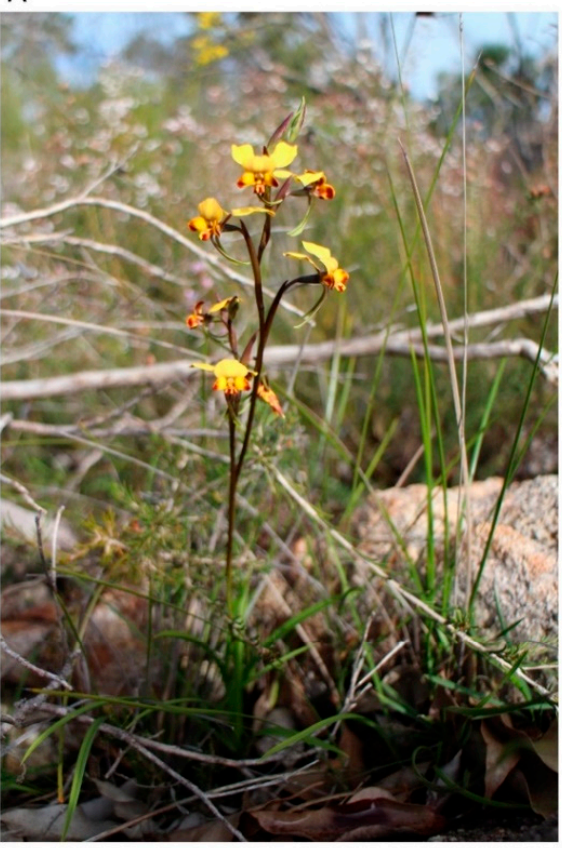

C

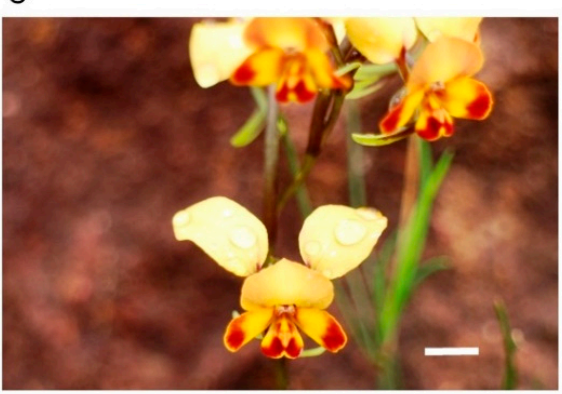

B

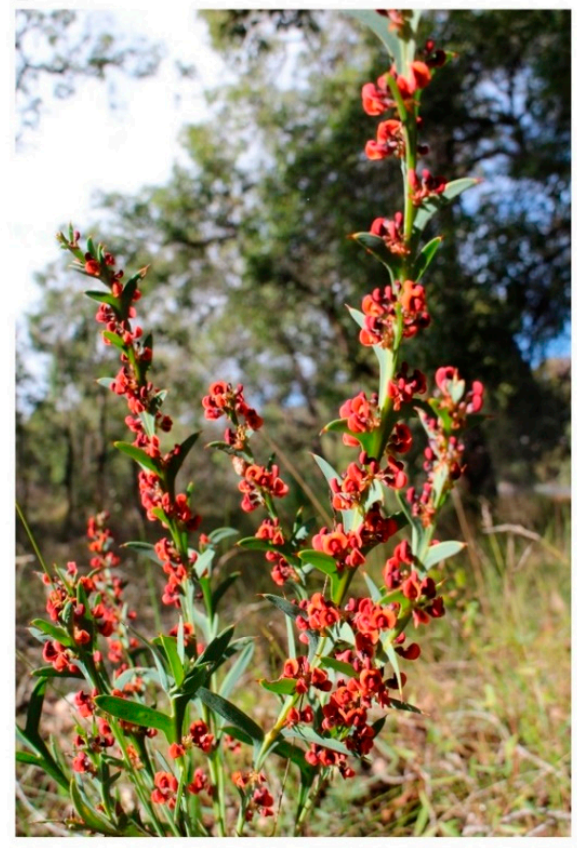

D

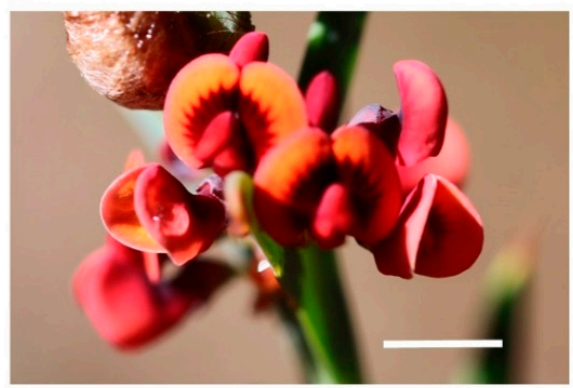

Figure 1. (A,C) The rewardless Diuris brumalis (Orchidaceae); (B,D) Daviesia decurrens (Faboideae), one of the model species involved in orchid floral mimicry. Scale bar: $5 \mathrm{~mm}$.

\section{Materials and Methods}

This study was undertaken at three sites in orchid-rich habitats in southwest Australia, $30 \mathrm{~km}$ east of Perth (32॰01'50.1" S, $116^{\circ} 06^{\prime} 01.2^{\prime \prime}$ E; $\left.32^{\circ} 01^{\prime} 41.9^{\prime \prime} \mathrm{S}, 116^{\circ} 05^{\prime} 41.7^{\prime \prime} \mathrm{E} ; 32^{\circ} 01^{\prime} 43.8^{\prime \prime} \mathrm{S}, 116^{\circ} 05^{\prime} 12.1^{\prime \prime} \mathrm{E}\right)$, where orchid populations were represented by a conspicuous number of plants $(>50)$. Observations were made over six sunny days during the orchid flowering period (12th, 18th and 25th July, and 2nd, 9th and 15th August 2016) when pollinators were expected to be active. Experiments were conducted for two days per site across the sampling period, between $10.30 \mathrm{a} . \mathrm{m}$. and 3.30 p.m., when temperatures were higher than $17^{\circ} \mathrm{C}$ (around the optimum for pollinator activity) [28], as detected by an electronic thermometer (Smartsensor AR827) set $20 \mathrm{~cm}$ above the ground.

Three experimental artificial arrays of orchid flowers comprised two inflorescences (with 4-6 flowers each) that had been cut and placed in three glass vials filled with water and positioned to replicate the colony-forming pattern of D. brumalis (Figure 2). Vials were spaced 10-20 cm apart and positioned to create a conspicuous floral display, approximately one metre from flowering individuals of the model food pea-plant (Daviesia species). In fact, after some first attempts, we observed that this was a suitable distance between arrays of orchid flowers and model plants to induce bees to visit orchid arrays that were, at the same time, adequately far away to draw a distinct foraging bout. A total of four model plants randomly chosen per site were used. The arrays were rotated in the following manner: every $15 \mathrm{~min}$ (including a minute for moving the arrays of orchid flowers), the vials were moved in proximity to another model plant. A period of $15 \mathrm{~min}$ (the maximum period 
of the trial applied in sexually deceptive orchids [17]) was sufficiently adequate for flower recognition and visitation by insects. The experiment was repeated hourly for 20 replicates ( $15 \mathrm{~min}$ each) per day, moving the orchid arrays in rotation among the same four selected model plants (Figure 3), accounting for a total of $30 \mathrm{~h}$.

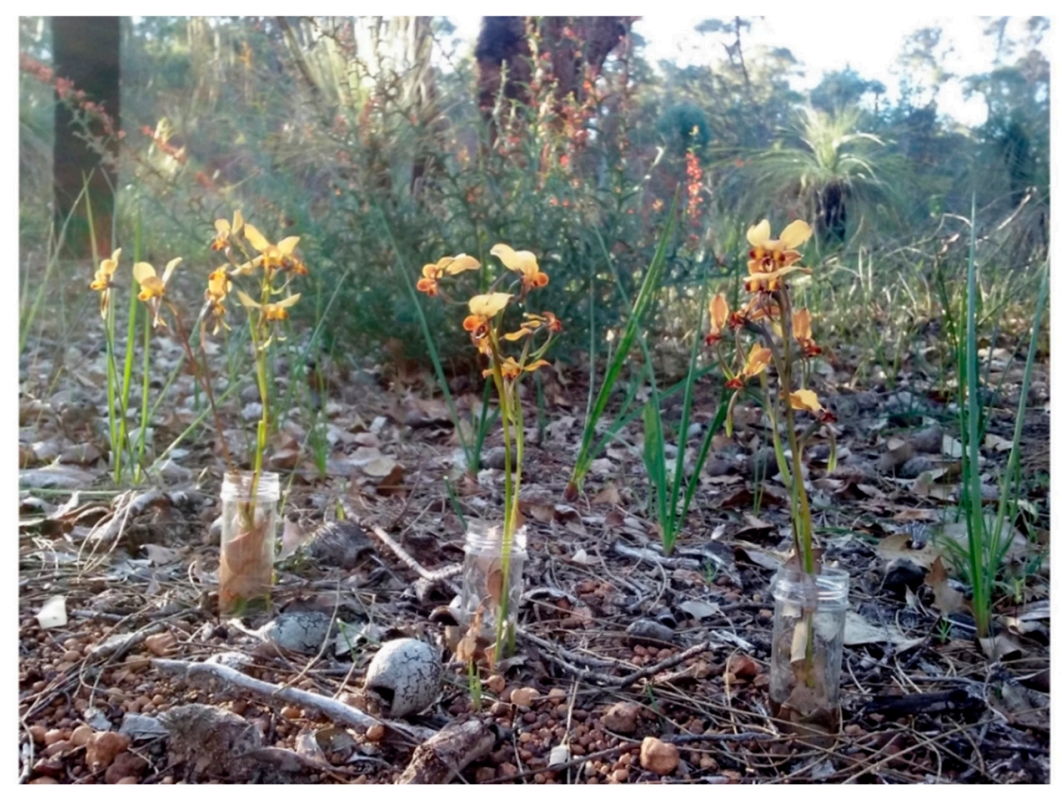

Figure 2. Arrays of orchid flowers of Diuris brumalis (Orchidaceae), presenting two stems in each of the three vials. In the background: a model plant of genus Daviesia (Fabaceae), used for studying the pollination.

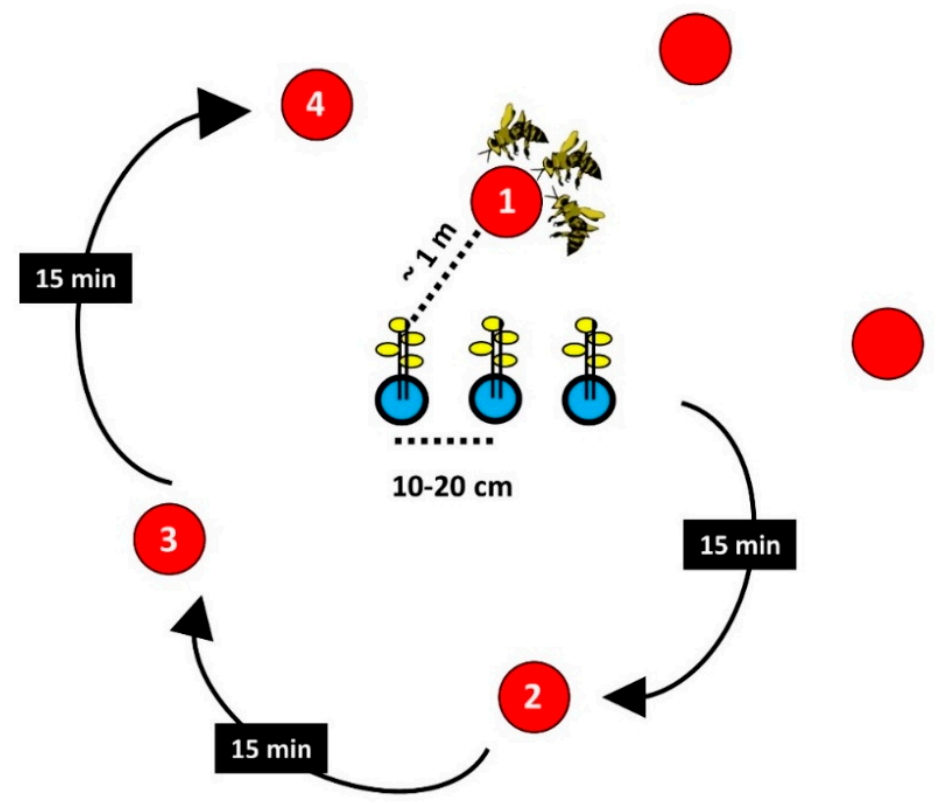

Figure 3. Representation of arrays of rotating orchid flowers used to establish pollinator effectiveness in Diuris brumalis (Orchidaceae). Filled red circles: model plants (Daviesia; Fabaceae); arrays of flowers in water in the open blue circles (vials), each containing two inflorescences of the mimic orchid D. brumalis.

Each orchid flower in the arrays had pollinaria at the beginning of the experiment. At the end of each day we scored pollinaria removal from intact clumps of flowering orchids. Observations were conducted on the same day over the same time frame (in total $30 \mathrm{~h}$ ), and the new natural orchid clump from which to score pollinaria removal was selected daily. Floral display was standardised based on 
flower abundance by selecting natural orchid clumps comprising at least the same number of flowers displayed by arrays of orchid inflorescences. To validate the effectiveness of these artificial arrays, a pairwise comparison was performed by using the G-test GenAlEx 6.5 [32,33], based on the total pollinaria removed in the three experimental artificial arrays and in the natural orchid clumps in the same site. A final recommendation is provided for storing the orchid inflorescences and re-using them for more days: as firstly done by [21,34], picked inflorescences can be maintained fresh up to 3-4 days (before flowers start to wither) in plastic or glass sample vials stored in a refrigerator at $4^{\circ} \mathrm{C}$, with some water in the bottom, and covering the inflorescence with a plastic bag.

To exclude any bias due to the location of arrays in proximity to target food plants, the approach was applied between 10.30 a.m. and 3.30 p.m. over four days using the previous experimental timeframe, accounting for a total of $20 \mathrm{~h}$, using food plants other than Daviesia that are common in understory vegetation (Acacia pulchella R.Br., Adenanthos barbiger Lindl., Bossiaea aquifolium Benth., Calothamnus sanguineus Labill., Hakea lissocarpha R.Br., Hibbertia hypericoides (DC.) Benth, Hovea chorizemifolia (Sweet) DC., Hovea pungens Benth. and Hypocalymna robustum Endl.). In total, we performed eight observations per plant ( $15 \mathrm{~min}$ each) and we accounted for pollinaria removed on orchid flowers in the array.

\section{Results}

The test showed a significant difference between pollinaria removed $(n=9)$ in natural orchid clumps $(\mathrm{N}$ total flowers $=200)$ and pollinaria removed $(n=31)$ in rotating arrays of orchid flowers in proximity to Daviesia plants ( $\mathrm{N}$ total flowers $=180$ ), with a higher and consistent outcome for the latter $\left(G_{\mathrm{df}}=16.731_{1}, p<0.001\right.$; Figure $\left.4 \mathrm{~A}\right)$. A total of 68 Trichocolletes spp. bees visited the arrays of orchid flowers, and only one bee deposited pollinaria on the stigma (Figure 4B). Visitation rate was highest between 11.30 a.m. and 12.30 p.m., while pollinaria removal was highest between 12.30 p.m. and 2.30 p.m. (Figure 4B). Arrays of orchid flowers placed in proximity to the other food plants (i.e., non-model plants) had no pollinaria removed. We also established that there was no bias due to the vicinity of arrays to food plants (Acacia pulchella, Adenanthos barbiger, Bossiaea aquifolium, Calothamnus sanguineus, Hakea lissocarpha, Hibbertia hypericoides, Hovea chorizemifolia, Hovea pungens, and Hypocalymna robustum) and confirmed the orchid pollinator sharing only with Daviesia plants. Exclusively, the proximity of orchid arrays to model plants on which Trichocolletes were intensively foraging led the bees to visit orchid arrays. Rotating arrays of orchid flowers resulted in a practical, robust and quicker approach for attracting pollinators to D. brumalis than traditional observations.
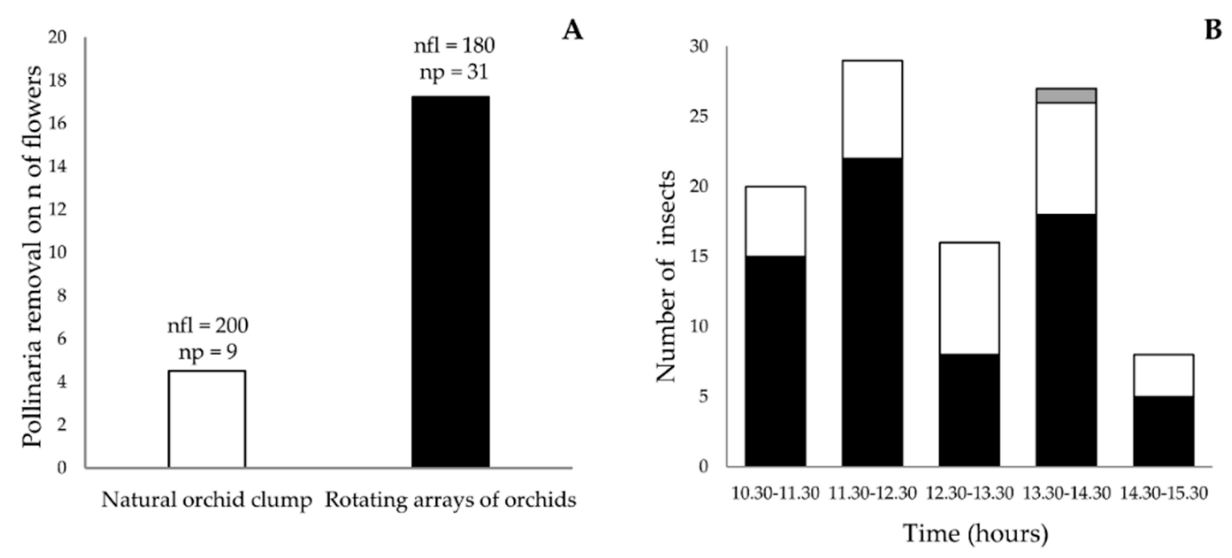

Figure 4. A Proportion of flowers of Diuris brumalis (Orchidaceae) with pollinaria removal in orchid clumps in their natural setting compared to rotating arrays of orchid flowers near model plants (Daviesia; Fabaceae). The proportion is based on six days of experiments across three sites. nfl: number of flowers; np: number of pollinaria removed. B Number of total visiting insects Trichocolletes spp. (Colletidae) (black), insects removing pollinaria (white) and depositing pollinia (grey) over time (hours) in six days of experiments involving rotating arrays of orchid flowers. 


\section{Discussion}

For the first time, the effectiveness of rotating arrays of orchid flowers to increase pollinator visits in food deceptive orchid systems with very low insect pollination success has been confirmed. Random baiting and choice experiments were not successful in attracting pollinators when applied in D. brumalis. This may be due to the very low insect visitation rates and effectiveness of the methods, constrained respectively by the presence of males and nest sites (Table 1). In the case of sexually deceptive orchids where attraction operates via sexual pheromones, orchid baits randomly placed in the landscape attract their male pollinators thanks to the sexually appealing compounds released, even if the orchids are distant from their pollinators [35]. However, the attraction is not warranted in food deceptive orchids that do not release pheromones. In "choice experiments", proximity to nest sites is crucial for the method's effectiveness [20], but in the case of solitary bees like Trichocolletes, it is not always feasible to find nest sites surfacing on the ground. In addition, just one female bee builds an individual nest, limiting the possibility of insect attraction to rare events [36]. Random bait trials were used in studying generalised deceptive orchids, and similarly, the proximity to nest sites potentially influenced the method's effectiveness (Table 1). It would be interesting to use rotating arrays of orchid flowers near a suite of food plants (or alternatively generic model plants close to orchids), encompassing a "general flower image" [37] when orchids have a very low fruit set (i.e., $<10 \%$ ).

The application of rotating arrays provided a continuous, refreshed landscape of orchid floral displays. Moreover, the effectiveness of using arrays of orchid flowers is likely to be influenced by the periodical moving of orchids close to various model plants. This would result in reducing the "learning behaviour" of visiting insects when static displays are presented [38] and the consequent avoidance of non-rewarding plants previously visited [39]. The peak of pollinaria removal was highest in the afternoon, suggesting that bees continued to visit and remove pollinaria after visiting flowers in the morning and were not conditioned by previous visits. This agrees with the expectation that mimics that are surrounded by other mimics should receive fewer visits than those that are surrounded by models [40]. This method has also been successfully applied in a congeneric food deceptive orchid species, Diuris magnifica D.L.Jones [41]. In contrast to D. brumalis [41], D. magnifica occupies a different habitat and mimics a broad range of model species, employing more generalised mimicry. Both orchid species had very low and similar pollination success with approximately $3 \%$ fruit set $[28,41]$. Even though the method was used but not validated in D. magnifica, it still allowed confirmation of the pollination strategy suggesting its potential to be applied to other food deceptive orchids, ranging from Batesian floral mimicry, where model species are engaged, to more generalised deception [37]. Indeed, orchid baiting has also been applied to study pollination of Caladenia R.Br. spp. that produces meagre amounts of nectar and is pollinated via nectar-foraging insects [42-45] (Table 1, i.e., C. versicolor G.W.Carr and C. concolor W.Fitzg.). However, in these latter cases, the method consisted of using randomly located bait trials through the landscape, while the "rotating arrays of orchid flowers" method was customised for more specialised forms of floral deception such as Batesian floral mimicry (Table 1). Depending on the visitation rate, the orchid pollination mechanism and the study aim, a panel of methodologies, summarised in Table 1, can be employed to effectively conduct the investigation.

Although our experimental approach is relatively simple, we found that its application can greatly increase the success of a pollination study to overcome the limitations caused by observation time and climate factors. Our approach allows observation of a higher pollinator rate, shortening the number of observations, and reducing significantly the time typically required to observe stationary plants. In general, we suggest this method be used for behavioural, ecological and mimicry studies as it (i) can reveal the behaviour of the visiting insect in a quick and effective manner, (ii) ensure sufficient and consistent replicates for data analysis and (iii) confirm the identity of model plants. In fact, even though putative models are often identified based on floral traits' resemblance to mimicked plants, "pollinator sharing" between the model and the mimic is the fundamental criterion for assessing floral mimicry [41]. 
We also suggest that this approach may be applied to pollination studies on other plants with low pollinator visitation rates. For shrubs and trees, parts of plants such as branches with flowers can be used as flower arrays. In this case, arrays of flowers can be placed and moved in proximity to magnet species [24] that increase the local abundance of pollinators (cf. [46]), or in sites characterized by a high presence of potential pollinators (i.e., close to food plants), so favouring more visits to the target species.

\section{Recommendations}

The method is recommended for studying pollination in food deceptive orchids with very low pollination rates $(<10 \%$; see Table 1$)$.

Use of potted plants is recommended in the case of rare or endangered species, if picking individual flowers may affect the conservation status of a species. This would also help if olfactory cues are employed by the study species. In fact, picked flowers can emit a significantly lower amount of volatiles than unpicked flowers, with variation in the odour bouquet that decreases their attraction to pollinators [47]. The current method is also potentially constrained by the presence of model plants and their abundance. However, multiple inflorescences of model plants can also be picked and located in orchid populations where model plants are absent. This represents an alternative approach when orchid species are rare or endangered and/or emit scent: instead of picking orchid inflorescences, it is recommended that inflorescences of the model plants are picked (or food / magnet plants for more generalised pollination mechanisms), "reversing" the experimental setup by rotating putative models compared to naturally growing orchids.

\section{Conclusions}

We recommend the use of using rotating arrays of flowers to study the pollination strategies of deceptive orchids, and to measure pollinator effectiveness across different habitats and ecosystems. In particular, the use of this approach enhances the visitation rate of pollinators and shortens the time required for pollinator observations, particularly for pollination studies on food deceptive orchids where observation of potential pollinators is often very difficult and time-consuming.

Author Contributions: Conceptualization, D.S.; validation, D.S.; formal analysis, D.S., A.G.; writing-review and editing, D.S., A.G., S.C., K.W.D.; supervision, S.C., K.W.D. All authors have read and agreed to the published version of the manuscript.

Funding: This work was supported by the Endeavour Fellowship Program [ID 5117_2016], the Australian Orchid Foundation [308.16], Università degli Studi di Napoli Federico II [Short mobility program D.M. 976_2017].

Acknowledgments: We thank Andrea Aromatisi for supporting the fieldwork activities and Lynne Milne and Tony Scalzo for advice. We are grateful to the editor and anonymous reviewers for suggestions that improved the final manuscript.

Conflicts of Interest: The authors declare no conflicts of interest.

\section{References}

1. Renner, S.S. Rewardless Flowers in the Angiosperms and the Role of Insect Cognition in Their Evolution. Plant-Pollinator Interactions: From specialization to Generalization; University of Chicago Press: Chicago, IL, USA, 2007; pp. 123-244.

2. Ackerman, J. Mechanisms and evolution of food-deceptive pollination systems in orchids. Lindleyana 1986, 1, 108-113.

3. Nilsson, L.A. Deep flowers for long tongues. Trends Ecol. Evol. 1998, 13, 259-260. [CrossRef]

4. Jersáková, J.; Johnson, S.D.; Kindlmann, P. Mechanisms and evolution of deceptive pollination in orchids. Biol. Rev. Camb. Philos. Soc. 2006, 81, 219-235. [CrossRef] [PubMed]

5. Kunze, J.; Gumbert, A. The combined effect of color and odor on flower choice behavior of bumble bees in flower mimicry systems. Behav. Ecol. 2001, 12, 447-456. [CrossRef] 
6. Galizia, C.G.; Kunze, J.; Gumbert, A.; Borg-Karlson, A.K.; Sachse, S.; Markl, C.; Menzel, R. Relationship of visual and olfactory signal parameters in a food-deceptive flower mimicry system. Behav. Ecol. 2005, 16, 159-168. [CrossRef]

7. Jersáková, J.; Jürgens, A.; Šmilauer, P.; Johnson, S.D. The evolution of floral mimicry: Identifying traits that visually attract pollinators. Funct. Ecol. 2012, 26, 1381-1389. [CrossRef]

8. Van der Cingel, N.A. An Atlas of Orchid Pollination; Balkema Publishers: Rotterdam, The Netherlands, 2001.

9. Gill, D.E. Fruiting failure, pollination inefficiency, and speciation in orchids. In Speciation and Its Consequences; Otte, D., Endler, J.A., Eds.; Academy of Natural Sciences Publications: Philadelphia, PA, USA, 1989; pp. $458-481$.

10. Neiland, M.R.M.; Wilcock, C.C. Fruit set, nectar reward, and rarity in the Orchidaceae. Am. J. Bot. 1998, 85, 1657-1671. [CrossRef]

11. Tremblay, R.L.; Ackerman, J.D.; Zimmerman, J.K.; Calvo, R.N. Variation in sexual reproduction in orchids and its evolutionary consequences: A spasmodic journey to diversification. Biol. J. Linn. Soc. 2005, 84, 1-54. [CrossRef]

12. Scopece, G.; Juillet, N.; MÜller, A.; Schiestl, F.P.; Cozzolino, S. Pollinator attraction in Anacamptis papilionacea (Orchidaceae): A food or a sex promise? Plant Species Biol. 2009, 24, 109-114. [CrossRef]

13. Brundrett, M.C. A comprehensive study of Orchid seed production relative to pollination traits, plant density and climate in an urban reserve in Western Australia. Diversity 2019, 11, 123. [CrossRef]

14. Gumbert, A. Color choices by bumble bees (Bombus terrestris): Innate preferences and generalization after learning. Behav. Ecol. Sociobiol. 2000, 48, 36-43. [CrossRef]

15. Internicola, A.I.; Juillet, N.; Smithson, A.; Gigord, L.D.B. Experimental investigation of the effect of spatial aggregation on reproductive success in a rewardless orchid. Oecologia 2006, 150, 435-441. [CrossRef] [PubMed]

16. Stoutamire, W.P. Australian terrestrial orchids, thynnid wasps, and pseudocopulation. Am. Orchid Soc. Bull. 1974, 4, 13-18.

17. Peakall, R. Responses of male Zaspilothynnus trilobatus to females and the orchid it pollinates. Funct. Ecol. 1990, 4, 159-167. [CrossRef]

18. Schiestl, F.P.; Ayasse, M.; Paulus, H.F.; Lofstedt, C.; Hansson, B.S.; Ibarra, F.; Francke, W. Orchid pollination by sexual swindle. Nature 1999, 399, 421-422. [CrossRef]

19. Ayasse, M.; Schiestl, F.P.; Paulus, H.F.; Ibarra, F.; Francke, W. Pollinator attraction in a sexually deceptive orchid by means of unconventional chemicals. Proc. R. Soc. B Biol. Sci. 2003, 270, 517-522. [CrossRef]

20. Gaskett, A.C.; Winnick, C.G.; Herberstein, M.E. Orchid sexual deceit provokes ejaculation. Am. Nat. 2008, 171, E206-E212. [CrossRef]

21. Phillips, R.D.; Scaccabarozzi, D.; Retter, B.A.; Hayes, C.; Brown, G.R.; Dixon, K.W.; Peakall, R. Caught in the act: Pollination of sexually deceptive trap-flowers by fungus gnats in Pterostylis (Orchidaceae). Ann. Bot. 2014, 113, 629-641. [CrossRef]

22. Whitehead, M.R.; Peakall, R. Short-term but not long-term patch avoidance in an orchid-pollinating solitary wasp. Behav. Ecol. 2013, 24, 162-168. [CrossRef]

23. Cuervo, M.; Rakosy, D.; Martel, C.; Schulz, S.; Ayasse, M. Sexual Deception in the Eucera-Pollinated Ophrys leochroma: A Chemical Intermediate between Wasp- and Andrena-Pollinated Species. J. Chem. Ecol. 2017, 43, 469-479. [CrossRef]

24. Thomson, J.D. Effects of variation in inflorescence size and floral rewards on the visitation rates of traplining pollinators of Aralia hispida. Evol. Ecol. 1988, 2, 65-76. [CrossRef]

25. Johnson, S.D.; Nilsson, L.A. Pollen carryover, geitonogamy, and the evolution of deceptive pollination systems in orchids. Ecology 1999, 80, 2607-2619. [CrossRef]

26. Johnson, S.D. Batesian mimicry in the non-rewarding orchid Disa pulchra, and its consequences for pollinator behaviour. Biol. J. Linn. Soc. 2000, 71, 119-132. [CrossRef]

27. Johnson, S.D.; Peter, C.I.; Nilsson, L.A.; Ågren, J. Pollination success in a deceptive orchid is enhanced by co-occurring rewarding magnet plants. Ecology 2003, 84, 2919-2927. [CrossRef]

28. Scaccabarozzi, D.; Cozzolino, S.; Guzzetti, L.; Galimberti, A.; Milne, L.; Dixon, K.W.; Phillips, R.D. Masquerading as pea plants: Behavioural and morphological evidence for mimicry of multiple models in an Australian orchid. Ann. Bot. 2018, 122, 1061-1073. [CrossRef]

29. Western Australian Herbarium. FloraBase-The Western Australian Flora. Department of Biodiversity, Conservation and Attractions. 1998. Available online: https://florabase.dpaw.wa.gov.au/ (accessed on 12 May 2020). 
30. Dixon, K.W.; Buirchell, B.J.; Collins, M.T. Orchids of Western Australia: Cultivation and Natural History, 2nd ed.; Western Australian Native Orchid Study and Conservation Group: Victoria Park, Perth, Australia, 1989.

31. Scaccabarozzi, D.; Dixon, K.W.; Tomlinson, S.; Milne, L.; Bohman, B.; Phillips, R.D.; Cozzolino, S. Pronounced differences in visitation by potential pollinators to co-occurring species of Fabaceae in the Southwest Australian biodiversity hotspot. Bot. J. Linn. Soc. in press. [CrossRef]

32. Peakall, R.; Smouse, P.E. GENALEX 6: Genetic analysis in Excel. Population genetic software for teaching and research. Mol. Ecol. Notes 2006, 6, 288-295. [CrossRef]

33. Peakall, R.; Smouse, P.E. GenALEx 6.5: Genetic analysis in Excel. Population genetic software for teaching and research-an update. Bioinformatics 2012, 28, 2537-2539. [CrossRef]

34. Bower, C.C. Specific pollinators reveal a cryptic taxon in the bird orchid, Chiloglottis valida sensu lato (Orchidaceae) in south-eastern Australia. Aust. J. Bot. 2006, 54, 53-64. [CrossRef]

35. Wong, B.B.; Salzmann, C.; Schiestl, F.P. Pollinator attractiveness increases with distance from flowering orchids. Proc. R. Soc. B 2004, 271, S212-S214. [CrossRef]

36. Batra, S.W. Solitary bees. Sci. Am. 1984, 250, 120-127. [CrossRef]

37. Johnson, S.D.; Schiestl, F.P. Floral mimicry; Oxford University Press: Oxford, UK, 2016.

38. Dyer, F.C. Spatial memory and navigation by honeybees on the scale of the foraging range. J. Exp. Biol. 1996, 199, 147-154. [PubMed]

39. Goulson, D.; Hawson, S.A.; Stout, J.C. Foraging bumblebees avoid owers already visited by conspecifics or by other bumblebee species. Anim. Behav. 1998, 55, 199-206. [CrossRef] [PubMed]

40. Anderson, B.; Johnson, S.D. The effects of floral mimics and models on each others' fitness. Proc. R. Soc. B 2006, 273, 969-974. [CrossRef]

41. Scaccabarozzi, D.; Guzzetti, L.; Phillips, R.D.; Milne, L.; Tommasi, N.; Cozzolino, S.; Dixon, K.D. Ecological factors affecting pollination success in an orchid that mimics multiple species of pea plants (Faboideae). Bot. J. Linn. Soc.. submitted. [CrossRef]

42. Reiter, N.; Bohman, B.; Flematti, G.R.; Phillips, R.D. Pollination by nectar-foraging thynnine wasps: Evidence of a new specialized pollination system for Australian orchids. Bot. J. Linn. Soc. 2018, 188, 327-337. [CrossRef]

43. Reiter, N.; Bohman, B.; Batley, M.; Phillips, R.D. Pollination of an endangered Caladenia species (Orchidaceae) by nectar-foraging behaviour of a widespread species of colletid bee. Bot. J. Linn. Soc. 2019, 189, 83-98. [CrossRef]

44. Reiter, N.; Bohman, B.; Freestone, M.; Brown, G.R.; Phillips, R.D. Pollination by nectar-foraging thynnine wasps in the endangered Caladenia arenaria and Caladenia concolor (Orchidaceae). Aust. J. Bot. 2019, 67, 490-500. [CrossRef]

45. Phillips, R.D.; Bohman, B.; Brown, G.R.; Tomlinson, S.; Peakall, R. A specialised pollination system using nectar-seeking thynnine wasps in Caladenia nobilis (Orchidaceae). Plant Biol. 2020, 22, 157-166. [CrossRef]

46. Kunin, W.E. Sex and the single mustard: Population density and pollinator behavior effects on seed-set. Ecology 1993, 74, 2145-2160. [CrossRef]

47. Schiestl, F.P.; Ayasse, M.; Paulus, H.F.; Erdmann, D.; Francke, W. Variation of floral scent emission and postpollination changes in individual flowers of Ophrys sphegodes subsp. sphegodes. J. Chem. Ecol. 1997, 12, 2881-2895. [CrossRef]

(C) 2020 by the authors. Licensee MDPI, Basel, Switzerland. This article is an open access article distributed under the terms and conditions of the Creative Commons Attribution (CC BY) license (http://creativecommons.org/licenses/by/4.0/). 